\title{
Two Cases of Severe Dementia Showing Dramatic Improvement after Denture Placement
}

\author{
Yoshiro Fujii \\ Shin Kobe Dental Clinic, Kobe City, Japan \\ Email: shin-kobe-dentalclinic@s9.dion.ne.jp
}

Received 2 April 2016; accepted 6 June 2016; published 9 June 2016

Copyright (C) 2016 by author and Scientific Research Publishing Inc. This work is licensed under the Creative Commons Attribution International License (CC BY). http://creativecommons.org/licenses/by/4.0/ (c) () Open Access

\section{Abstract}

Severe dementia, including Alzheimer's disease, is intractable and progressive. The purpose of this study was to document the improvement observed in two cases of severe dementia after denture placement. The subjects, two women in their $70 \mathrm{~s}$ with severe dementia, were diagnosed with Alzheimer's disease by the medical doctors in charge of their cases. In the first case, the subject's symptoms included severe disorientation, impaired communication, and a tendency to wander. Two weeks after a lower complete denture placement, she was able to greet others. Five weeks later, she was able to communicate and precisely read an analog clock. Her condition continued to improve for at least 3 months. In the second case, the subject's mouth was always open. She was bedridden in a vegetative state and hardly moved, talked, or laughed; it was impossible to communicate with her. Only a few seconds after an upper complete denture placement, she started to talk, albeit unintelligibly. Two weeks after a lower complete denture placement, she could communicate normally, laugh, and walk without help. Although the underlying mechanism has not yet been clarified, the author hypothesizes that positive signals from the oral area are transferred to the brain as positive stimulation via the trigeminal nerve, the largest cranial nerve.

\section{Keywords}

Dementia, Alzheimer's Disease, Complete Denture, Dental Treatment, Trigeminal Nerve

\section{Introduction}

Dementia is disorder of particular concern because the decline in memory and other cognitive functions that characterize this condition result in a loss of independent function that has a wide-ranging impact on individuals, 
families, and healthcare systems [1]. Dementia is not a specific disease but an overall term that describes a wide range of symptoms associated with a decline in memory or other thinking skills severe enough to reduce a person's ability to perform everyday activities. Alzheimer's disease accounts for $60 \%-80 \%$ of dementia cases. For most progressive dementias, including Alzheimer's disease, there is no cure or treatment available that slows or stops its progression [2]. According to the Alzheimer's Society (https://www.alzheimers.org.uk/), the number of people living with dementia is increasing. The total cost of dementia worldwide is USD 604 billion. By 2050 it is projected that there will be 115 million people with dementia worldwide. Since the spread of dementia is threat for mankind, we have to establish an effective treatment for dementia as soon as possible. The author hypothesizes that oral stimulation has an effect on cognitive function. For example after yawning, it's wakeful. Therefore, the author tried to treat severe dementia by means of dental technique. This report describes two case studies of severe dementia diagnosed as Alzheimer's disease that dramatically improved via dental treatment using artificial dentures without any noticeable side effects.

\section{Case Reports}

\subsection{Case 1}

The subject was a woman in her 70s with severe dementia diagnosed as Alzheimer's disease by the medical doctor in charge of her case. Her dementia symptoms started several years prior to this study, and the disease continued to worsen. Her dementia symptoms were too severe to allow her to be nursed at home, and she was hospitalized approximately 1 year before her first dental treatment. Her symptoms included severe disorientation and impaired communication; as she could not understand where she was, or recall her name. It was impossible to communicate with her. When she visited the dental treatment room of the hospital, she tried to close a window at the reception desk to prevent a thief from entering, and she began to wander around on her hands and knees (Figure 1). She responded when we asked questions, but the meaning was always unclear. She did not reply when her name was called. She was constantly moving her mouth (oral dyskinesia). She had no history of cerebrovascular disease. Since she was not diagnosed with any other diseases related to dementia, she was not prescribed any medications or treatments. Although almost all the teeth in her upper jaw were intact, the lower jaw was completely edentulous. She did not have any dentures.

A lower complete denture was fabricated to correct the abnormalities in the subject's hippocampus representative area shown by the Bi-Digital O-Ring Test [3] [4]. When the lower complete denture was placed in her mouth, her oral dyskinesia immediately ceased (Figure 2). Two weeks after the lower complete denture placement, she became more aware of her surroundings and was able to respond to the greeting "Hello" (Figure 3). However, when the denture was removed, her dyskinesia reappeared, and her expression dimmed rapidly (Figure 4). Five weeks later, she was able to converse normally and was also able to precisely read an analog clock. Her condition continued to improve for at least 3 months until she left the hospital. Video of this patient's progress can be found on YouTube (Dental treatment for dementia Part 1:

https://www.youtube.com/watch?v=2mVTzPBh8mY).

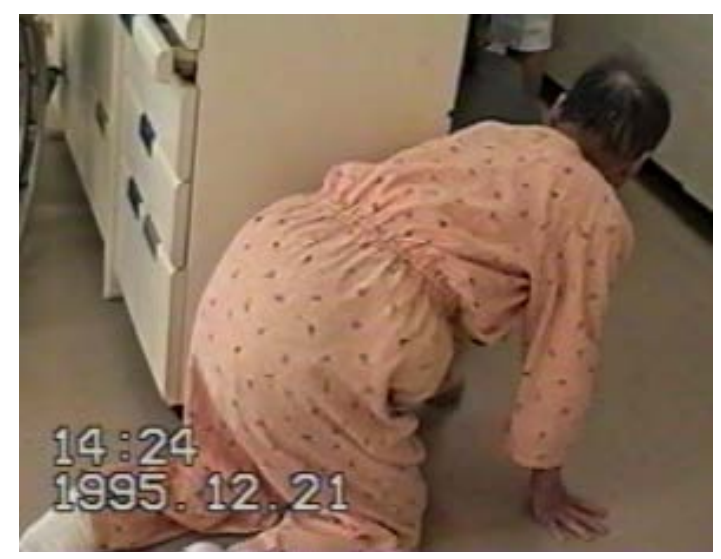

Figure 1. The patient wandering in the dental treatment room of the hospital. 


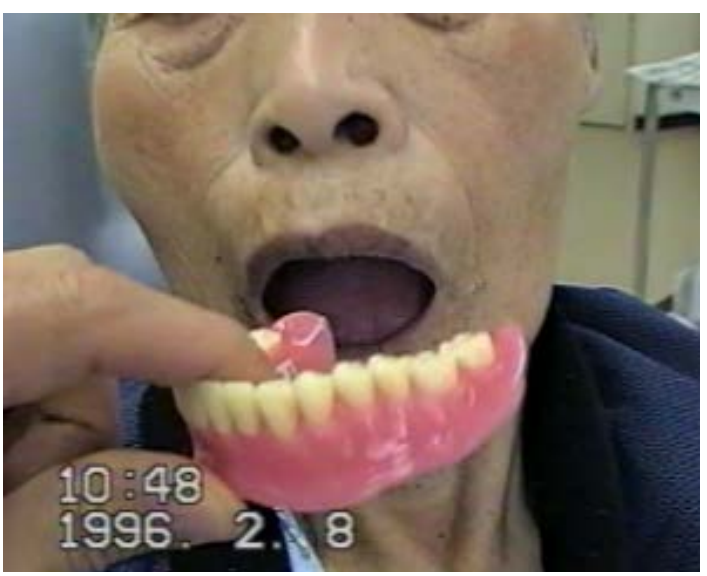

Figure 2. A lower complete denture being placed in the patient's mouth.

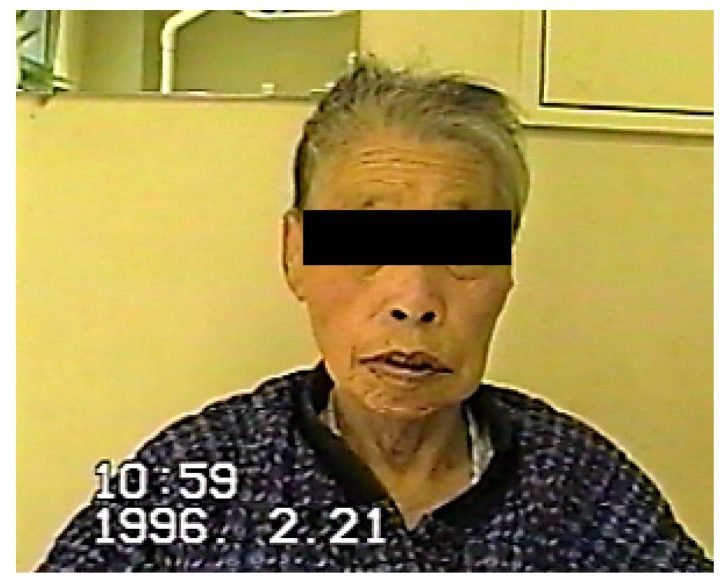

Figure 3. The patient at 2 weeks after receiving a lower complete denture was more aware of her surroundings.

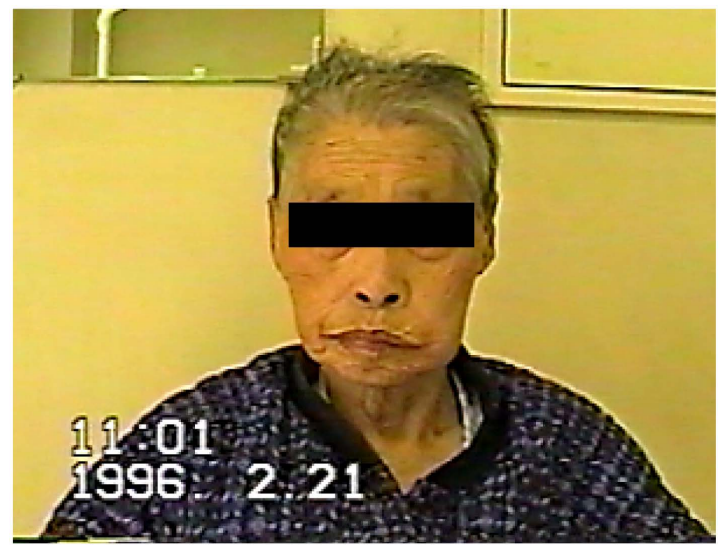

Figure 4. When the denture was removed, the patient's dyskinesia reappeared, and her expressions dimmed rapidly.

\subsection{Case 2}

The subject was a woman in her 70s with severe dementia that was diagnosed as Alzheimer's disease by the 
medical doctor in charge of her case. Her dementia symptoms had started several years previously, and the disease had continued to worsen. Since her dementia symptoms were too severe to be nursed at home, she had been hospitalized approximately 6 months before her first dental treatment. She had no history of cerebrovascular disease. Since she was not diagnosed with any other diseases related to dementia, she was not prescribed any medications or treatments. She constantly kept her mouth open. She was bedridden in a vegetative state and hardly moved, talked, or laughed (Figure 5). It was impossible to communicate with her. Although both her jaws were completely edentulous, she did not have any dentures.

A upper complete denture was fabricated to correct the abnormalities in the subject's hippocampus representative area shown by the Bi-Digital O-Ring Test [3] [4]. Only a few seconds after the upper complete denture placement, she started to talk, but the meaning was not clear. One month later, the lower complete denture was set. Two weeks after the lower complete denture placement, she could communicate normally, laugh and walk on her own without help (Figure 6). Her condition continued to improve for at least 3 months until she left the hospital. Video of this patient's progress can be observed on YouTube video (Dental treatment for dementia Part 2: https://www.youtube.com/watch?v=WfTnjYc-EzE).

\section{Discussion}

The functional assessment staging (FAST) scale [5] is used for staging the severity of dementia in patients diagnosed with Alzheimer's disease by evaluating the patient's highest consecutive level of disability (Table 1).

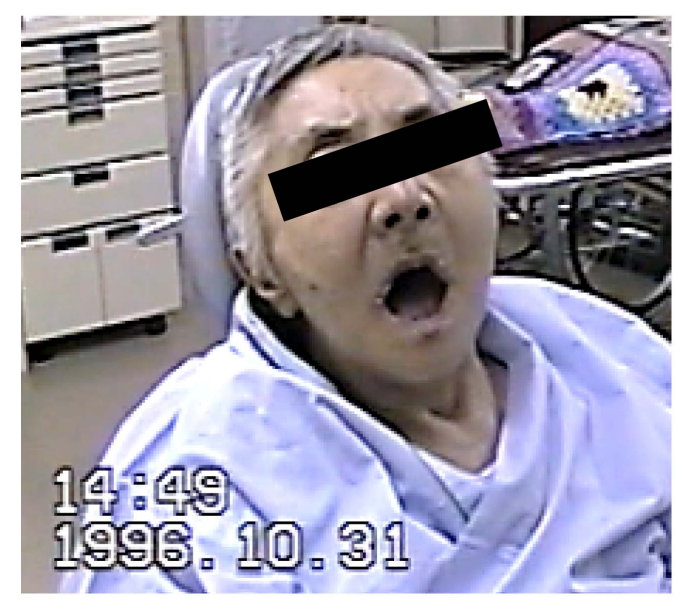

Figure 5. The patient before denture placement: she constantly kept her mouth open.

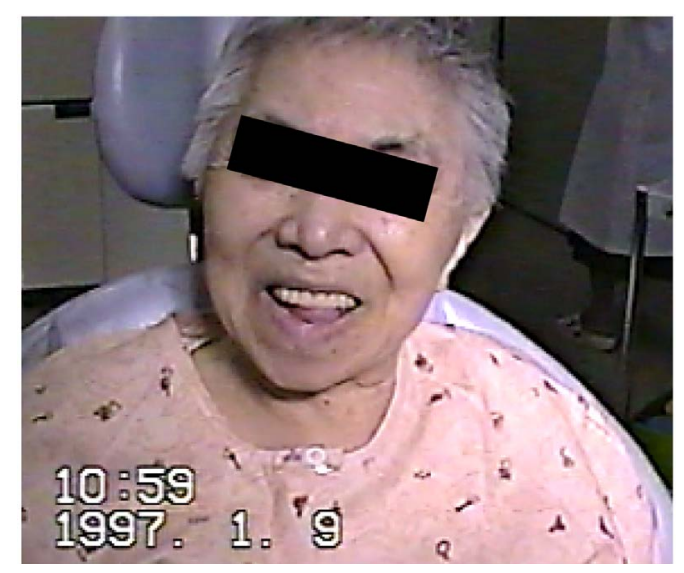

Figure 6. The patient at 2 weeks after the lower complete denture placement: she could communicate smoothly, laugh, and walk without help. 
Table 1. Functional assessment staging.

\begin{tabular}{|c|c|}
\hline Stage & Skill level \\
\hline 1 & No difficulty, either subjectively or objectively. \\
\hline 2 & Complains of forgetting location of objects. Subjective work difficulties. \\
\hline 3 & Decreased job functioning evident to coworkers; difficulty in traveling to new locations decreased organizational capacity. \\
\hline 4 & $\begin{array}{l}\text { Decreased ability to perform complex tasks, for example, planning dinner for guests, handling personal finances (forgetting } \\
\text { to pay bills), marketing. }\end{array}$ \\
\hline 5 & $\begin{array}{l}\text { Requires assistance in choosing proper clothing to wear for the day, season, or occasion, for example, patient may wear the } \\
\text { same clothing repeatedly, unless supervised. }\end{array}$ \\
\hline \multicolumn{2}{|l|}{6} \\
\hline $6 a$ & $\begin{array}{l}\text { Improperly putting on clothes without assistance or cues (e.g., may put street clothes on overnight clothes, put shoes on } \\
\text { wrong feet, or have difficulty buttoning clothing) occasionally or more frequently over the past weeks." }\end{array}$ \\
\hline $6 b$ & $\begin{array}{l}\text { Unable to bathe (shower) properly (e.g., difficulty adjusting bathwater or shower temperature) occasionally or more } \\
\text { frequently over the past weeks.* }\end{array}$ \\
\hline 6c & $\begin{array}{l}\text { Inability to handle mechanics of toileting (e.g., forgets to flush the toilet and does not wipe properly or properly dispose of } \\
\text { toilet tissue) occasionally or more frequently over the past weeks." }\end{array}$ \\
\hline $6 \mathrm{~d}$ & Urinary incontinence (occasionally or more frequently over the past weeks). ${ }^{*}$ \\
\hline $6 e$ & Fecal incontinence (occasionally or more frequently over the past weeks). ${ }^{*}$ \\
\hline \multicolumn{2}{|l|}{7} \\
\hline $7 a$ & $\begin{array}{l}\text { Ability to speak limited to approximately half a dozen or fewer intelligible different words in the course of an average day } \\
\text { or in the course of an intensive interview. }\end{array}$ \\
\hline $7 \mathrm{~b}$ & $\begin{array}{l}\text { Speech ability limited to the use of a single intelligible word in an average day or in the course of an interview (the person } \\
\text { may repeat the word over and over). }\end{array}$ \\
\hline 7c & Ambulatory ability lost (cannot walk without personal assistance). \\
\hline $7 \mathrm{~d}$ & Cannot sit up without assistance (e.g., the individual will fall over if there are no lateral rests (arms) on the chair). \\
\hline $7 e$ & Loss of ability to smile. \\
\hline $7 \mathrm{f}$ & Loss of ability to hold up head independently. \\
\hline
\end{tabular}

*Scored primarily on the basis of information obtained from a knowledgeable informant and/or caregiver. This table was cited from http://geriatrics.uthscsa.edu/tools/FAST.pdf.

For clinical purposes, in addition to staging the level of disability, additional, nonordinal (nonconsecutive) deficits should be noted, because these additional deficits are of clear clinical relevance. According to FAST, both cases presented here showed improvement from approximately stage 7 to stage 1 or 2 .

Treatment of dementia depends on its cause. In the case of most progressive dementias, including Alzheimer's disease, there is no cure or treatment available that slows or stops its progression [2]. The author has treated many patients with dementia. If the dementia is mild, the condition may disappear within 24 hours of the insertion of the dentures. The medication available for dementia treatment only delays the progression of the symptoms. However, this dental treatment has been shown not only to delay progression but also to reverse it in some cases. The author has reported a relationship between dental condition and systemic health [6]-[15]. The author is a dentist and therefore did not have access to magnetic resonance imaging. However, because the two subjects had no history of cerebrovascular disease, the author concluded that they did not have vascular dementia. Vascular dementia occurs after a stroke and is the second most common type of dementia [2]. Moreover, the subjects were not diagnosed with a specific form of dementia, and the doctor in charge of both cases diagnosed Alzheimer's disease, which accounts for $60 \%-80 \%$ of dementia cases [2]. Therefore, there was a very high possibility that the subjects had Alzheimer's disease. The underlying reason why this treatment was so dramatically successful remains unclear. More investigation is needed. The author hypothesizes that beneficial signals stimulate the brain via the trigeminal nerve, which is the largest of the 12 cranial nerves (Figure 7).

It has been suggested that the mouth exerts a strong influence on the brain. After completing dental treatment, the effects of the treatment continued for at least 3 months. The author was unable to follow the subjects after they left the hospital, and it is not clear whether this treatment actually improved the affected parts of the brain 


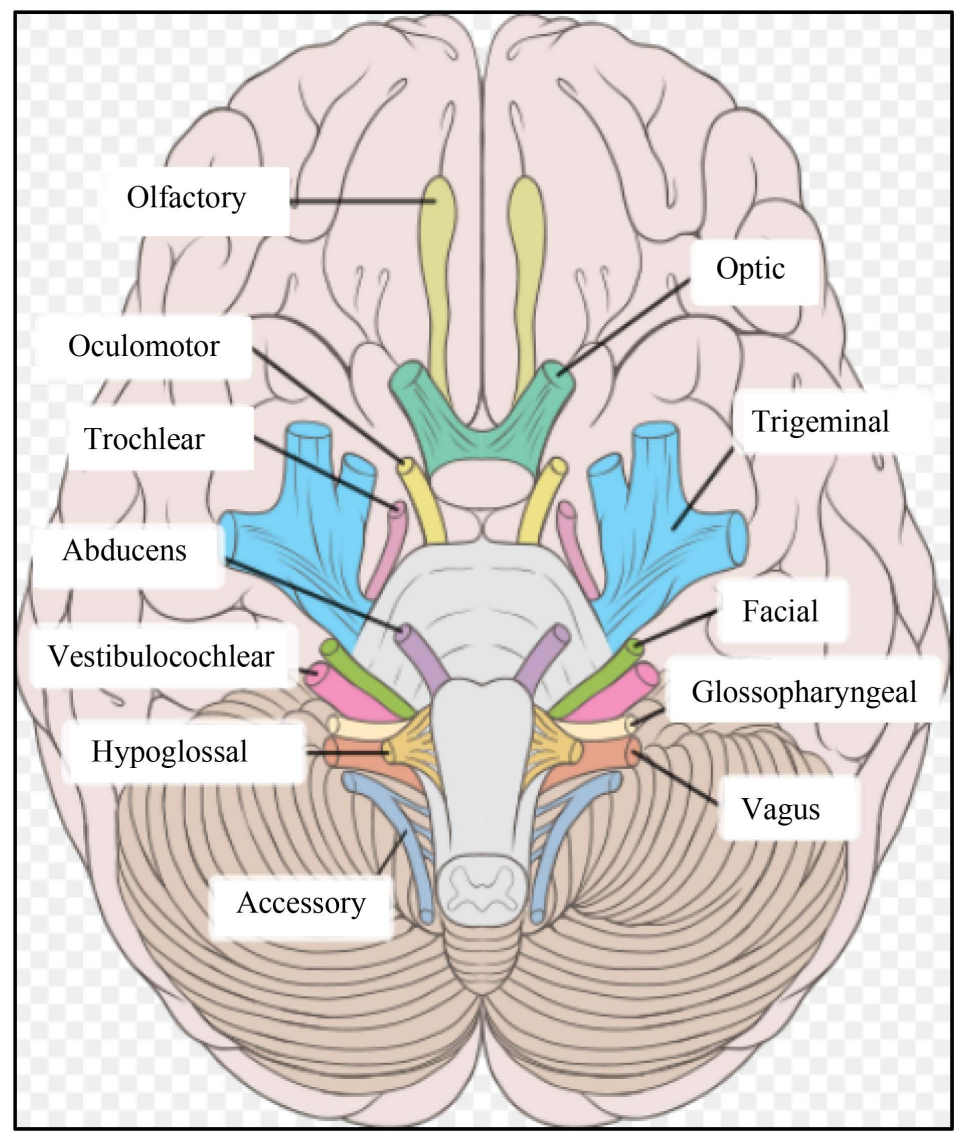

Figure 7. The trigeminal nerve is the largest of the 12 cranial nerves. This figure is reproduced from https://en.wikipedia.org/wiki/Cranial_nerves.

or the unaffected portions of the brain began to compensate for a loss of normal function. In this case study, this treatment had no reported side effects. It is especially difficult to explain this treatment to patients with dementia due their mental impairment, so the author used longer time to make the dentures than usual in these cases.

The sample size of this study is too small to establish the treatment's effectiveness. Further investigation is necessary.

\section{Conclusion}

After fitting and placing dentures in two patients with severe dementia suspected to be Alzheimer's disease, the author observed dramatic improvement of their dementia symptoms. It is generally believed that it is impossible to improve severe dementia. Thus it is noteworthy that dental treatment could provide such a remarkable improvement in a short time period. The author believes that dental treatment may be an effective option for patients with Alzheimer's disease. Denture placement is an extremely safe, quick, and convenient procedure, and the patients' symptoms dramatically improved in a very short time. However, the underlying mechanism has not been clarified. More research is needed with cooperation between dentistry and medicine.

\section{Additional Information}

Informed consent for publication was obtained from the subjects after these treatments.

\section{References}

[1] Plassman, B.L., Langa, K.M., Fisher, G.G., Herring, S.G., Weir, D.R., Ofstedal, M.B., Burke, J.R., Hurd, M.D., Potter, G.G., Rodgers, W.L., Steffens, D.C., Willis, R.J. and Wallace, R.B. (2007) Prevalence of Dementia in the United States: The Aging, Demographics, and Memory Study. Neuroepidemiology, 29, 125-132. 
http://dx.doi.org/10.1159/000109998

[2] http://www.alz.org/what-is-dementia.asp

[3] Omura, Y. (1993) Bi-Digital O-Ring Test for Imaging and Diagnosis of Internal Organs of a Patient. US Patent 5188107. http://academic.reed.edu/economics/parker/f11/354/pat/o-ring.pdf

[4] http://bdort.org/

[5] Reisberg, B. (1988) Functional Assessment Staging (FAST). Psychopharmacology Bulletin, 24, 653-659.

[6] Fujii, Y. (2012) Do Dental Implants Cause Scoliosis? Case Report. Personalized Medicine Universe, 1, 79-80. http://dx.doi.org/10.1016/j.pmu.2012.05.012

[7] Fujii, Y. (2014) Gold Alloy Dental Inlay for Preventing Involuntary Body Movements Caused by Electromagnetic Waves Emitted by a Cell Phone. Open Journal of Antennas and Propagation, 2, 37-43. http://dx.doi.org/10.4236/ojapr.2014.24005

[8] Fujii, Y. (2014) Sensation of Balance Dysregulation Caused/Aggravated by a Collection of Electromagnetic Waves in a Dental Implant. Open Journal of Antennas and Propagation, 2, 29-35. http://dx.doi.org/10.4236/ojapr.2014.23004

[9] Fujii, Y. (2015) Dental Stimulation to the Buccal Mucous Membrane Causes Lumbago: A Report of Two Cases. Case Reports in Clinical Medicine, 4, 289-296. http://dx.doi.org/10.4236/crcm.2015.48058

[10] Fujii, Y. (2015) Calling into Question the Efficacy of Evidence-Based Medicine: Is It Always the Best Approach? Is That Really the Placebo Effect? Natural Science, 7, 165-170. http://dx.doi.org/10.4236/ns.2015.74019

[11] Fujii, Y. (2015) Dental Treatment for Dizziness and Joint Mobility Disorder Caused by Harmful Electromagnetic Waves. Open Journal of Antennas and Propagation, 3, 1-7. http://dx.doi.org/10.4236/ojapr.2015.31001

[12] Fujii, Y. (2015) Orthodontic Treatment to Improve Hip Joint Mobility and Balance. Journal of Dentist, 3, $29-32$. http://dx.doi.org/10.12974/2311-8695.2015.03.01.5

[13] Fujii, Y. (2015) Use of Dental Inlay for Treatment of Hip Joint Dysregulation: A Case Report. Case Reports in Clinical Medicine, 4, 356-365. http://dx.doi.org/10.4236/crcm.2015.411072

[14] Fujii, Y. (2015) Electromagnetic Waves Collected by a Dental Amalgam Filling Induced Balance Dysregulation and Dizziness over a Period Exceeding 10 Years. Open Journal of Stomatology, 5, 235-242. http://dx.doi.org/10.4236/ojst.2015.510029

[15] Fujii, Y. (2016) Improvement of Systemic Symptoms after Dental Implant Removal. Open Journal of Stomatology, 6, 37-46. http://dx.doi.org/10.4236/ojst.2016.62005 